\title{
Effects of low doses of gamma rays on the stability of normal and diabetic erythrocytes
}

\author{
Magdalena Kaczmarska1, Zofia Kopyściańska1, Maria Fornal2 ${ }^{2}$ Tomasz Grodzicki², \\ Krzysztof Matlak¹, Józef Korecki and Květoslava Burda1凶
}

${ }^{1}$ AGH University of Science and Technology, Faculty of Physics and Applied Computer Science, Kraków, Poland; ${ }^{2}$ Collegium Medicum, Jagiellonian University, Department of Internal Medicine and Gerontology, Kraków, Poland

\begin{abstract}
We studied the influence of low doses of $\gamma$ radiation (from 0.04 to $1.8 \mathrm{mGy}$ ) on the stability of human red blood cells (RBC) from healthy donors and diabetic patients using absorption spectroscopy. Because of the alteration of many enzymatic pathways in diabetic RBCs resulting in strong modification of the lipid and protein membrane components one could expect that the ionizing $y$-radiation should influence the stability of the healthy and diabetic cells in a different way. Indeed, distinct discontinuities and monotonic changes of hemolysis detected in the healthy and diabetic RBCs suggest that various enzymatic and chemical processes are activated in these membranes by $\gamma$ radiation. Mössbauer measurements showed that only the highest applied dose of $\gamma$ radiation caused modification of hemoglobin in both types of RBCs.
\end{abstract}

Keywords: erythrocytes; diabetes; hemoglobin; $ү$ rays; hemolysis; absorption spectroscopy; Mössbauer spectroscopy

Received: 28 December, 2010; revised: 29 August, 2011; accepted: 06 October, 2011; available on-line: 08 November, 2011

\section{INTRODUCTION}

Highly reactive oxygen species (ROS) are natural byproducts of oxygen metabolism in living organisms. At physiological concentrations they play important protection and signaling roles but at higher concentrations they are harmful (Meyers, 1995). Under normal circumstances, cells are able to defend themselves against ROS damage. Biological effects of these highly reactive compounds are controlled in vivo by a wide spectrum of antioxidant mechanisms, as for example by the enzymes superoxide dismutases (SOD), glutathione peroxidase (GPx), catalases (CAT), peroxiredoxin, and also by small antioxidant molecules as carotenoids, tocopherols, ascorbic acid and glutathione (Meister, 1994; Bannister et al., 1987; Johnson et al., 2005; Chelikani et al., 2004; Padayatty et al., 2003; Bagchi et al., 1998; Preedy et al., 2007; Sies et al., 1996). Oxidative stress resulting from increased free-radical production or defects in the antioxidant defenses is implicated in the athogenesis of numerous diseases (Harman, 1992). At the molecular level increased peroxidation of lipids and proteins and even damage of DNA are observed in such cases.

ROS are also generated by exogenous sources, for example ionizing radiation. All living organisms are continuously exposed to background ionizing radiation coming from natural sources such as radioelements in the soil or cosmic radiation as well as man-made ionizing radiation (medical procedures, consumer products, for example food). It has been estimated that this background ionizing radiation amounts to about $2.5 \mathrm{mSv}$ per year at the sea level but at some areas this dose rate is enhanced by a factor of 3 to 10 (high-level natural background radiation) (Lowenthal et al., 1997; Tsun-Yee Chiu et al., 1997). It is well known that high doses of ionizing radiation (exceeding $200 \mathrm{mSv}$, which corresponds to 200 $\mathrm{mGy}$ for $\gamma$-radiation) result in overproduction of oxygenderived free radicals (Zaider et al., 1994; Trosco et al., 1997), which cause peroxidation of membrane proteins and lipids being the first targets of the ROS destructive action (Köteles, 1982). Further products of peroxidation are mutagenic and carcinogenic, for example the reactive malondialdehyde (Dainiak et al., 1995; Dainiak, 1997; Marnett, 1999; Marnett et al., 1994). However, lipid peroxidation is also produced at low doses of ionizing radiation, even close to the normal background one, independently of its type (X-ray or $\gamma$-radiation), (Petkau, 1971; Petkau 1972; Riley, 1994). Once initiated in the membrane, the damaging chain reactions propagate by themselves.

This work intends to study the radiation effects of low doses of $\gamma$-radiation (from $0.04 \mathrm{mGy}$ to $1.8 \mathrm{mGy}$ ) on the red blood cell (RBC) stability. The dose rate of $0.04 \mathrm{mGy}$ / min is only 8000 times higher than that from the background radiation which is about $5 \mathrm{nGy} / \mathrm{min}$. Usually the dose rates investigated exceed this value by tens of orders of magnitude (Gwoździński, 1991; Iyer et al., 2002; Szweda-Lewandowska et al., 2003; Kokosz et al., 2006). $\gamma$-Radiation doses of 500-1000 Gy induced alterations of the RBC membrane at the level of lipid bilayer and skeleton proteins influencing in this way the membrane permeability and cell stability as well as hemoglobin states inside the cells (Shapiro et al., 1968; Gwoździński, 1991; Iyer et al., 2002). Much less is known about the cellular response to low doses of ionizing radiation such as those typical for medical diagnostic procedures, normal occupational exposures or cosmic-ray exposures at flight altitudes, and there are only a few reports on their action on RBCs. For example, $\gamma$-irradiation (or X-irradiation) of blood components with doses of $25-50$ Gy is used to prevent posttransfusion-associated graft-versus-host dis-

e-mail: burda@novell.ftj.agh.edu.pl

Abbreviations: CAT, catalse; GPx, glutathione peroxidase; $\mathrm{Hb}$, hemoglobin; OxyHb, oxygenated hemoglobin; MetHb, methemoglobin; RBC, red blood cell; SOD, superoxide dismutases; TA-GVHD, posttransfusion-associated graft-versus-host disease. 
ease, TA-GVHD, (Treleaven et al., 2011). However, this process has been demonstrated to cause an increase in the permeability of the RBC membrane to potassium, sodium, hemoglobin and lactate dehydrogenase (LDH) (Hirayama et al., 2005; Agarwal et al., 2005; Zimmermann et al., 2011; Bashir et al., 2011). It was also shown that exposure to $\gamma$-rays with doses of 25 Gy significantly increased the RBC volume and lipid peroxidation. The deformability of the irradiated RBCs was significantly lower than that of non-irradiated cells (Kim et al., 2008). The decreased deformability of $\gamma$-ray-irradiated RBCs was independently confirmed by Cicha et al. (2000) but they did not observe an enhancement of lipid peroxidation, protein aggregation of the RBC membrane, or echinocytosis. Some of the contradictory results may originate from the differences in the medium used. Exposure of the whole body to single doses of $\gamma$-rays of 1 to $9 \mathrm{~Gy}$ revealed an increase of blood viscosity as a function of the dose from $1 \mathrm{~Gy}$ up to $7 \mathrm{~Gy}$ but for $9 \mathrm{~Gy}$ a decrease of viscosity was detected. In addition, the RBC membrane surface charge density decreased after irradiation by the lowest dose and continued to decrease with the increased dose, which was demonstrated by measuring the relative permittivity and relaxation time at the low frequency range in RBC membrane surface (Selim et al., 2009). Investigations of the biochemical and biophysical properties of human erythrocyte membranes after exposure to relatively low doses of $\gamma$ rays $(2,4$ and $8 \mathrm{~Gy}$ and the rate dose of $0.5 \mathrm{~Gy} / \mathrm{min}$ ), performed by Benderitter et al. (2003), showed that the lipid peroxidation increased with an increased postirradiation time (from 3 to $72 \mathrm{~h}$ ), whereas antioxidant activities of catalase and glutathione peroxidase decreased after irradiation and the change was more significant with increasing dose. The SOD activity had a similar behavior as catalase and glutathione peroxidase $3 \mathrm{~h}$ after exposure but at $72 \mathrm{~h}$ after exposure it increased with the increased dose of radiation. Those observations were made in relation to corresponding controls but it is interesting to mention that the SOD activity decreased significantly in the control sample after $72 \mathrm{~h}$ of incubation in comparison with the same sample after $3 \mathrm{~h}$ whereas the activities of catalase and glutathione peroxidase were comparable for both periods of incubation. In the case of skeleton proteins, spectrin and actin oxidation was highest for the lowest dose applied, i.e. 2 Gy for $3 \mathrm{~h}$ after irradiation. Then, actin oxidation decreased clearly with the increasing dose but spectrin oxidation stayed the same. All these modifications together with the detected increased content of the saturated phosphatidylethanolamine (PE) fatty acid and decreased content of the (n-3) and (n-6) series of PE fatty acids results in an increased fluidity of the membrane lipid compartment but increased rigidity of the lipid-protein membrane interface.

Basic research data and human epidemiological data show that cellular responses to low absorbed doses of ionizing radiation cannot be predicted by extrapolating from the responses to high doses. Numerous examples of 'radiation hormesis' and 'radioadaptive response' can be found in the literature (Meyer et al., 1998; Radivoyevitch et al., 2002; Cohen, 2008; Iyer \& Lehnert, 2002; Feinendegen, 2005; Chen et al., 2007). Depending on the type of adaptive protection in a given cell system, except for apoptosis and terminal cell differentiation, the adaptive response has a maximum for doses from $5 \mathrm{mGy}$ to $200 \mathrm{mGy}$ in most mammalian cells (Meyer et al., 1998). Recently, it has been found that the biological effects of low and high LET (linear energy transfer) radiations at low doses are very complex because of a newly observed phenomenon called the "bystander effect", when non-irradiated cells exhibit responses like those of the neighbouring irradiated cells (Azzam et al., 1998; 2001; Mothersill \& Seymour, 2001; Zhou et al., 2001; Nagasawa \& Little, 2001; Sgouros et al., 2007; Iyer \& Lehnert, 2002; Baskar, 2010). Positive biological effects of acute low doses (0.01-0.05 Gy) of $\gamma$-radiation on the erythrocyte membrane were demonstrated by Mahmoud et al. (2011). The same authors showed that higher doses of 0.2 and 0.3 Gy caused aggregation of proteins and changes of organization of phospholipids of the RBC membrane. However, within the framework of this study we concentrated on probing the effects of much lower doses of $\gamma$-radiation, from $0.04 \mathrm{mGy}$ to 1.8 $\mathrm{mGy}$, which are at least 1-3 orders of magnitude lower than those at which hormesis phenomena have been reported. Therefore all effects which are described in this paper could be related to the Petkau effect taking place when the propagation of free radicals is enhanced. It has been observed that $\mu \mathrm{Gy}$ doses can cause serious oxidative stress in living organisms and in addition at lower dose rates result in more severe damage to lipids and proteins, especially riche in -SH groups (Petkau, 1972; Graeub, 1994).

Taken together, these findings reinforce our understanding that the cell membrane is a significant biological target of radiation. Thus the role of the biological membrane in the expression and course of cell damage after radiation exposure must be considered. Both $\mathrm{OH}^{-}$and $\mathrm{O}_{2} \bullet-$ radicals play a role in the initiation of lipid peroxidation in human erythrocytes (Purohit et al., 1980a; 1980b; Köteles, 1982). Because of the Petkau effect one may expect that under our experimental conditions hemolysis of irradiated RBCs should be observed and it should depend on the state of the RBC membrane. Although RBC is not a very radiosensitive cell, it is a suitable candidate for monitoring the radiation effects because: (i) it is a representative sample for the whole body exposure, (ii) it is easy to obtain RBC with an intact membrane, (iii) the RBC membrane has a well known structure (Pasini et al., 2006) and (iv) RBC is very often used to monitor the stage of development of many diseases, for example of diabetes (Baynes et al., 1999). Therefore in our studies we chose RBCs isolated from the blood of healthy donors and diabetic patients. Diabetic disease is related to the metabolic perturbation or abnormal blood glucose homeostasis and chronic hyperglycemia (Ha et al., 1999; Baynes et al., 1999). In diabetic cases, modifications of RBC membrane properties and of RBC inner homeostasis have been reported (Ha et al., 1999; Nagamatsu et al., 1986; Waczulíková et al., 2000; Adak et al., 2008). These changes result mainly from an increased level of lipid and protein peroxidation as well as of glycooxidation products in diabetic RBCs in comparison to control RBCs (Resmi et al., 2001). There is even a glycooxidation hypothesis assuming that glycooxidation is responsible for the permanent, cumulative oxidative damage to long-lived proteins in aging and in diabetes (Baynes, 1991). In addition, it has been proven experimentally that many enzymatic reactions defending the erythrocyte membranes against ROS are altered in diabetic RBC membranes (Ha et al., 1999; Uzel et al., 1987; Stevens et al., 2000; Murakami et al., 1989; Yoshida et al., 1995; Thornalley et al., 1996; Lang et al., 1966; Venerando et al., 2002). Thus, irradiation of healthy and diabetic RBCs applying such a low rate of $\gamma$-radiation as $0.04 \mathrm{mGy} /$ 
min for a short time only (from 1 to $45 \mathrm{~min}$ ) allows us to follow differences in their sensitivity to $\gamma$-radiation. One should expect differences in their response to the oxidative stress induced by ionizing radiation knowing that the properties of diabetic RBCs vary from those of healthy RBCs. The percentage of hemolysis of RBCs treated with $\gamma$-rays was estimated from absorption measurements. Mössbauer spectroscopy, which is a sensitive tool for investigation of the iron valence and spin states as well as the type and arrangement of iron ligands (Lang et al., 1966; Burda et al., 1995), was applied to follow the states of hemoglobin $(\mathrm{Hb})$ in the untreated and irradiated erythrocytes.

\section{MATERIALS AND METHODS}

Erythrocytes were isolated from blood via centrifugation in phosphate buffer, $\mathrm{pH} 7.4$ using a standard method (Burda et al., 2002). Five millilitres of blood was taken and heparin was added as an anti-coagulant. The blood was centrifuged $\left(4500 \mathrm{rpm}, 4^{\circ} \mathrm{C}\right)$ for $20 \mathrm{~min}$ and the pellet collected. Pelleted cells were suspended in phosphate buffer pH $7.4\left(\mathrm{NaH}_{2} \mathrm{PO}_{4} / \mathrm{Na}_{2} \mathrm{HPO}_{4}, 200 \mathrm{mM}\right)$ and centrifuged again $\left(4500 \mathrm{rpm}, 4^{\circ} \mathrm{C}\right)$. This procedure was repeated 3 times. Washed RBCs were suspended in the phosphate buffer at $4 \times 10^{9} \mathrm{red}$ blood cells $/ \mathrm{ml}$. For the Mössbauer experiments about 20-fold concentrated samples having a total volume of about $1.5 \mathrm{ml}$ were used. These samples were kept frozen at $-80^{\circ} \mathrm{C}$.

${ }^{137} \mathrm{Cs}$ was used as the source of $\gamma$ rays. Its activity was $0.181 \mathrm{GBq}$ and the dose rate was $0.04 \mathrm{mGy} /$ min. Samples were exposed to the $\gamma$-radiation for different periods from $1 \mathrm{~min}$ to $45 \mathrm{~min}$. TLD-LiF: $\mathrm{Mg}, \mathrm{Cu}, \mathrm{P}$ (MCP-N) detectors, with a $4.5 \mathrm{~mm}$ diameter and $0.9 \mathrm{~mm}$ thickness were used to control the doses. The detectors were calibrated before each experiment.

Hemolysis was monitored by measuring of absorption spectra of supernatant, obtained from non-irradiated and irradietd samples centrifigated after their incubation at room temperature in darkness, between $450 \mathrm{~nm}$ to 700 nm. A UV-2101 Shimadzu PC scanning spectrophotometer was used. Percentage of hemolysis was determined from the ratio of the area under the absorption peak centered at $577 \mathrm{~nm}$ of an irradiated sample to that of a corresponding non-irradiated, totally hemolyzed sample. The spontaneous hemolysis of a control (nonirradiated) sample was subtracted. All results were normalized to the amount of erythrocytes in the samples. Only freshly prepared RBCs were used in those studies.

By applying Mössbauer spectroscopy we could monitor the valence and spin state of the heme-iron in hemoglobin in the control and irradiated RBCs. This gave us information on the state of hemoglobin and its ability to bind $\mathrm{O}_{2} \cdot{ }^{57} \mathrm{Co}(\mathrm{Rh})(50 \mathrm{mCi})$ was the source of the $14.4 \mathrm{keV} \gamma$-radiation. The measurements were performed at $85 \mathrm{~K}$. Temperature was stabilized within 0.1 K. Experimental data were fitted using Recoil Mössbauer Spectral Analysis Software (Rancourt et al., 1991).

The experiments were carried out in agreement with a permission from the Bioethical Commission $\mathrm{KBET} / 11 / \mathrm{B} / 2009$.

\section{RESULTS}

We studied the influence of low doses of $\gamma$-radiation on the stability of RBCs for four different cases of healthy and diabetic donors.

\section{Hemolysis}

The rate of spontaneous hemolysis of control, nonirradiated RBC samples, kept at room temperature, (RT $=22 \pm 2{ }^{\circ} \mathrm{C}$ ) for $24 \mathrm{~h}$, did not exceed $0.2-0.4 \%$. This value was always subtracted from the rate of hemolysis, detected for irradiated RBCs from healthy and diabetic
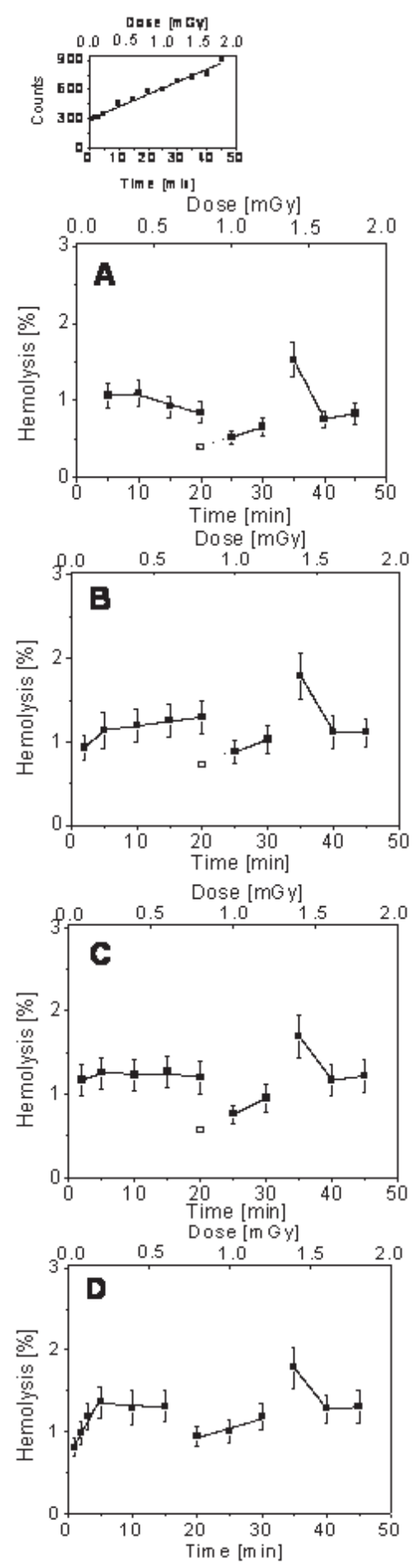

Figure 1. Dependence of hemolysis of RBCs from healthy donors on the time of irradiation by $\mathrm{Y}$-rays.

Upper graph shows a calibration curve of LTD detectors. Empty symbols show extrapolated points. Each experimental point is an average from three independent measurements. Parts A-D correspond to RBCs obtained from four donors. 
donors stored at RT for $24 \mathrm{~h}$, which did not exceed $2 \%$ and $4 \%$, respectively. These values are $2.5-5$ times higher than that admissible by clinical guidelines for the storage of RBCs to be used in transfusion (hemolysis should be less than $0.8 \%$ ). However, the solutions that support the metabolic demands of RBCs stored for transfusion contain additionally citrate, and dextrose (CPD) as well as osmoprotectants that stabilize the $\mathrm{RBC}$ membrane
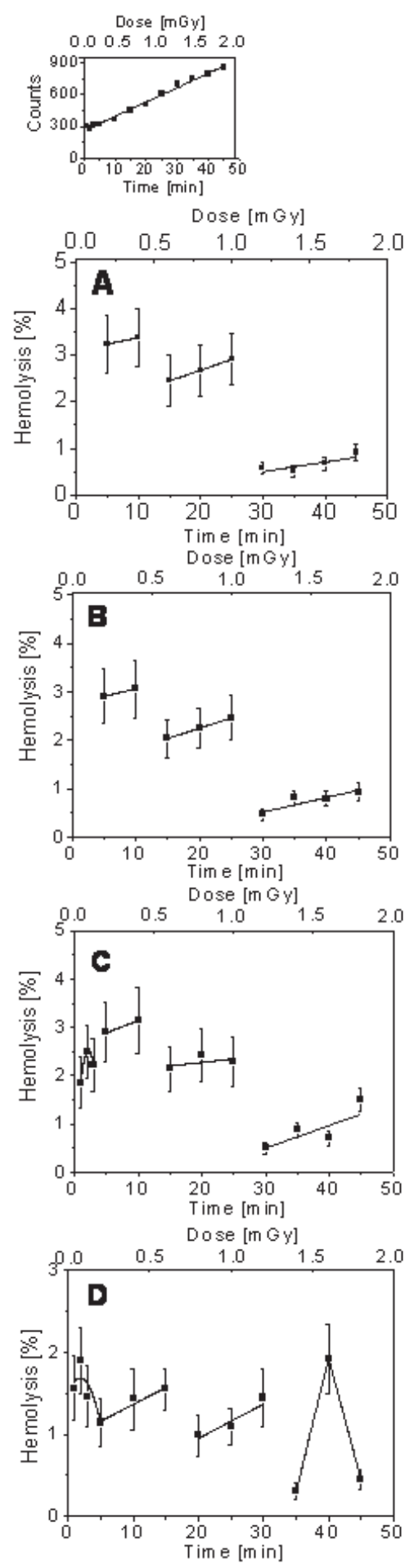

Figure 2. Dependence of hemolysis of RBCs from diabetic donors on the time of irradiation by $\mathrm{Y}$-rays.

Upper graph shows a calibration curve of LTD detectors. Each experimental point is an average from three independent measurements. Parts A-D correspond to RBCs obtained from four donors. and maintain 2,3-diphosphoglycenate and ATP within the erythrocyte, for example mannitol. They are absent in our buffer. When RBCs are supplemented with additional preservative solutions (i.e., Adsol, Nutricell, or Optisol) they can be stored at $0-6^{\circ} \mathrm{C}$ for up to 42 days and their hemolysis does not exceed $1 \%$. Moreover, addition of glycerol allows RBCs to be frozen at temperatures below $-65^{\circ} \mathrm{C}$ and thus extends the period of safe storage up to 10 years (Fasano \& Luban, 2008). When needed, RBCs are deglycerolized by washing and such $\mathrm{RBC}$ units suspended in standard saline have to be transfused within 24 hours of preparation. It is known that the washing itself causes electrolyte leakage and therefore the RBC unit should be transfused as soon as possible after being washed (Weiskopf et al., 2005). Thus, the rate of hemolysis detected by us in the case of non-irradiated RBCs from healthy donors is in accordance with the observations described above, although our buffer does not contain all the stabilizers and nutrients. The increased hemolysis in irradiated samples could also be expected because in our case RBCs were stored at RT only in phosphate buffer. It is known that $\gamma$-irradiation of cellular blood components at 20-50 Gy in order to prtect patients of TA-GVHD causes increased leakage of potassium and $\mathrm{Hb}$ even at $0-6^{\circ} \mathrm{C}$ and despite the presence of all the necessary components stabilizing the erythrocyte membrane (Pelsynski et al., 1994; Davey et al., 1992).

The percentage of hemolysis of RBCs isolated from healthy and diabetic donors as a function of the $\gamma$ - irradiation dose (time), are shown in Fig. 1 and Fig. 2, respectively.

In the case of RBCs isolated from healthy donors, one can distinguish five characteristic periods of irradiation when hemolysis changes monotonically (Fig. 1). The first time range from 1 to 5 minutes is characterized by an increase of hemolysis, which is then stabilized at about $1.15 \pm 0.15 \%$ for the time of irradiation from $5 \mathrm{~min}$ to $20 \mathrm{~min}$ (in one case to $15 \mathrm{~min}$, Fig. 1D). For $20 \mathrm{~min}$ of irradiation, i.e., for the dose of $0.8 \mathrm{mGy}$, a discontinuity of hemolysis is observed when its value decreases about 2 -fold. Then hemolysis increases monotonically for the exposure time up to $30 \mathrm{~min}$. Between $30-35 \mathrm{~min}$ one observes a second discontinuity of the hemolysis which increases by a factor of about 1.7. For the irradiation time $\geq 35 \mathrm{~min}$ hemolysis decreases and then is stabilized between $40-45 \mathrm{~min}$ on the level of about $1 \%$.

For RBCs of diabetic donors suffering from noninsulin-dependent diabetes mellitus (diabetes mellitus of type 2) the dependence of hemolysis on the exposure time to $\gamma$-rays is different from that of RBCs from healthy donors (Fig. 2). Moreover, it depends on the degree of the severity of the disease. Figure $2 \mathrm{~A}-\mathrm{C}$ shows data for diabetes which cannot be managed by dietary modification alone. For these three severe diabetic cases three characteristic time periods of a monotonic increase of hemolysis are visible. They are separated by two discontinuities: (i) at 10-15 min, when hemolysis decreases to about $2 \%$ and $1 \%$ for the more and less severe diabetes, respectively, and (ii) at 25-30 min, when hemolysis decreases by a factor of about 5 . In the time range from 5 to 10 minutes hemolysis exceeds $3 \%$, from 15 to $25 \mathrm{~min}$ it changes between $2-2.5 \%$, whereas in the time range from 30 to $45 \mathrm{~min}$ hemolysis increases only from 0.5 to $1 \%$. Measurements performed for irradiation times shorter than $5 \mathrm{~min}$ show that there is a maximum of hemolysis at $2 \mathrm{~min}$ of exposure to $\gamma$-rays as it was observed for the less severe diabetic case when dietary modification is sufficient (Fig. 2C and 2D). In the latter 


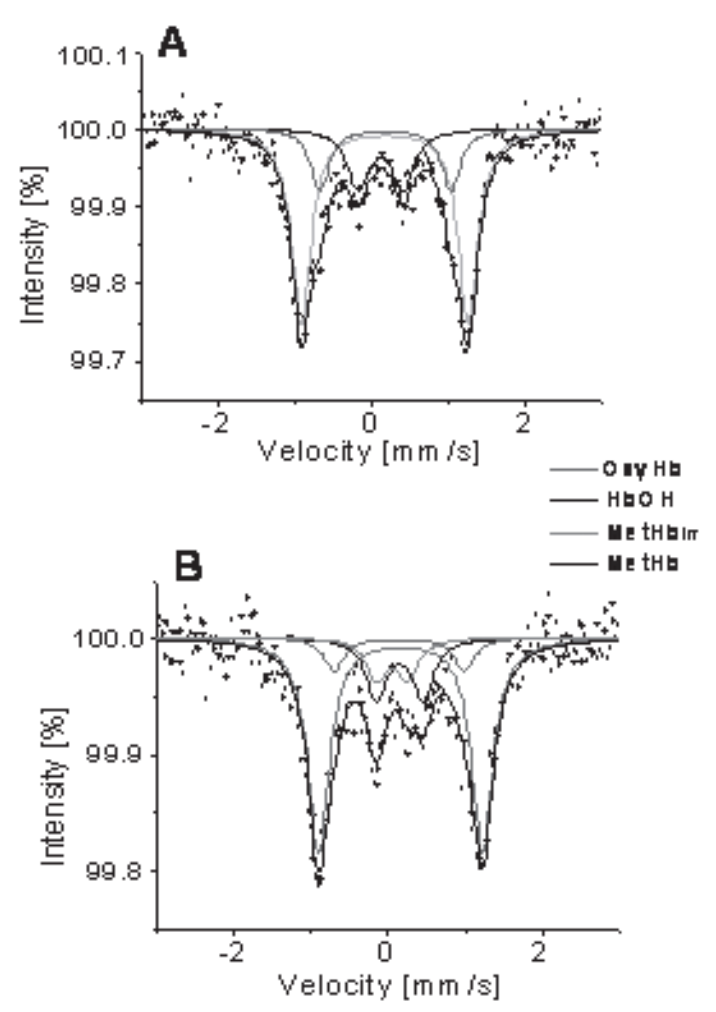

Figure 3. Mössbauer spectra of RBCs from a diabtetic donor non-irradiated $(A)$ or irradiated $(B)$ with $1.8 \mathrm{mGy}$ of $\gamma$-rays.

case the monotonic behaviour of hemolysis resembles the data obtained for other diabetics but there are some important differences: (i) the percentage of hemolysis for the characteristic time periods of $\gamma$-irradiation between $5-25 \mathrm{~min}$ is lower on average by a factor of 2, (ii) the characteristic discontinuities are shifted towards shorter times of irradiation (lower doses) and are now observed at $15 \mathrm{~min}$ and $30 \mathrm{~min}$, and (iii) an additional maximum of hemolysis is observed at $40 \mathrm{~min}$.

Comparing the dependence of hemolysis on the time of irradiation, i.e., on the dose absorbed, between normal and diabetic samples, one sees that the hemolysis of RBCs from diabetic donors is about 2-3 times higher than that of healthy RBCs for doses $\leq 1.2 \mathrm{mGy}$, but is lower by a factor of 2 for doses from 1.2 to 1.8 $\mathrm{mGy}$. The monotonic change of hemolysis observed in healthy cases for the dose of about $1.6 \mathrm{mGy}$ disappears and an additional maximum occurs at 2 min of irradiation, i.e., for $0.08 \mathrm{mGy}$, in the diabetic cases. Moreover, the other characteristic discontinuities of hemolysis are shifted towards lower doses by $0.2 \mathrm{mGy}$ ( $5 \mathrm{~min}$ shorter exposure times for the dose rate of 0.04 $\mathrm{mGy} / \mathrm{min}$ ). The characteritic time periods (dose ranges) seem to be related to the protective mechanisms activated within the red cells. Because it is well documented in the literature that all acute antioxidant processes related to the action of glutathione, peroxidase, SOD and catalase are diminished in the diabetic erythrocytes and result in an increased peroxidation of lipids in their membrane (Bayens \& Thorpe, 1994; Uzel et al., 1987; Stevens et al., 2000; Thomalley et al., 1996; Yoshida et al., 1995; Murakami et al., 1995), we infer that such acute mechanisms activated in healthy RBC membrane are attenuated in the case of diabetes. Moreover, the degree of activity of these processes depends on the dose of irradiation and time after exposure (Benderit- ter et al., 2003). Therefore the observed differences in the membrane stability of the $\gamma$-irradiated erythrocytes from normal and diabetic individuals could be due to the different enzymatic repair processes which are activated in these cases. These mechanisms clearly show variable sensitivity, which results in the observed different discontinuities and monotonicities in the two cases studied. The results obtained for the diabetic donors confirm that the stage of the disease can be monitored by changes of the stability of RBC exposed to low doses of $\gamma$-radiation.

\section{Mössbauer measurements}

In order to check the possible influence of $\gamma$ rays on the homeostasis within erythrocytes, the states of haemoglobin $(\mathrm{Hb})$ inside RBC were controlled via measurements of spin and valence states of the heme-iron applying Mössbauer spectroscopy. This method is also sensitive to changes of the type and arrangement of iron ligands (G.Lang et al. 1966; Burda et al., 1995).

We observed an effect of $\gamma$-radiation on the $\mathrm{Hb}$ states only for the highest applied dose of $1.8 \mathrm{mGy}$ (45 min of irradiation). Representative Mössbauer spectra of nonirradiated and irradiated RBCs isolated from blood of a severe diabetic donor are shown in Fig. 3A and Fig. 3B, respectively. Because the irradiation affects the $\mathrm{Hb}$ states in the healthy RBCs in a similar way we do not present the data here. Values of hyperfine parameters fitted to the experimental spectra obtained for both cases are collected in Table 1.

The Mössbauer spectra of untreated RBCs can be decomposed into three components characterized by different hyperfine parameters. These doublets have comparable isomer shifts (IS) within the experimental error but they differ in the values of quadrupole splitting (QS) (Table 1). The component with the largest QS of about $2.17 \mathrm{~mm} / \mathrm{s}$ characterizes a low spin ferrous state in oxygenated haemoglobin $\left(\mathrm{HbO}_{2}=\mathrm{OxyHb}\right)$. The doublet with QS about $1.70 \mathrm{~mm} / \mathrm{s}$ has to be assigned to deoxyhemoglobin in which $\mathrm{OH}$ is the 6th ligand of the heme-iron $(\mathrm{HbOH})$ and in this case the heme-iron is in a mixed valence state $\left(\mathrm{Fe}^{2+} / \mathrm{Fe}^{3+}\right)$ having mixed spin states. The third component with QS about $0.55 \mathrm{~mm} / \mathrm{s}$ comes from methemoglobin with a five-coordinated heme-iron in a high spin ferric state (MetHb) (Lang et al. 1966; Suzdalev, 1988). These three subspectra are detected in the Mössbauer spectra of RBCs from healthy and diabetic donors but the contributions of the components are different in these two types of RBCs. In both cases the highest contribution is that of $\mathrm{OxyHb}$, however, in the diabetic RBCs its content is significantly lower by about $6 \%$. The contribution of $\mathrm{HbOH}$ is comparable in healthy and diabetic RBCs but the content of MetHb is almost 2-fold higher in the latter case.

Irradiation of RBCs does not change the content of $\mathrm{OxyHb}$ but results in a new component in the Mössbauer spectra. The contribution of this component in healthy and diabetic RBCs is at the level of about $12 \%$ (Fig. 3B and Table 1). At the same time the contributions of $\mathrm{HbOH}$ and $\mathrm{MetHb}$ decrease. Because this new doublet is characterized by IS of about $0.07 \mathrm{~mm} / \mathrm{s}$ and by QS of about $0.47 \mathrm{~mm} / \mathrm{s}$ and it originates from methemoglobins it can be assigned to methemoglobin $\left(\mathrm{MetHb}_{\text {irr. }}\right)$ with a five-coordinated heme-iron in a high-spin oxidized state and with the protein structure modified in proximity of the iron binding site (Mössbauer spectroscopy can detect only rearrangement of the first coordination sphere of the probed atom). 
Table 1. Representative hyperfine parameters fitted to Mössbauer spectra obtained for non-irradiated and irradiated RBCs isolated from healthy and diabetic donors.

Changes of $\mathrm{Hb}$ states (inside RBCs) were observed only for the highest applied dose of $\gamma$-radiation, 1.8 mGy. IS, isomer shift; QS, quadrupole splitting. The line width was $0.20 \pm 0.02 \mathrm{~mm} / \mathrm{s}$.

\begin{tabular}{|c|c|c|c|c|}
\hline & $\mathrm{OxyHb}$ & $\mathrm{HbOH}$ & MetHb & $\mathrm{MetHb}_{\mathrm{irr}}$ \\
\hline \multicolumn{5}{|c|}{ Healthy donor, control } \\
\hline $\mathrm{CS}[\mathrm{mm} / \mathrm{s}]$ & $0.16 \pm 0.01$ & $0.18 \pm 0.02$ & $0.14 \pm 0.05$ & \\
\hline $\mathrm{QS}[\mathrm{mm} / \mathrm{s}]$ & $2.17 \pm 0.03$ & $1.74 \pm 0.08$ & $0.55 \pm 0.08$ & \\
\hline Contribution [\%] & $67.4 \pm 0.5$ & $20.2 \pm 1.5$ & $12.3 \pm 1.5$ & \\
\hline \multicolumn{5}{|c|}{ Healthy donor, after irradiation } \\
\hline $\mathrm{CS}[\mathrm{mm} / \mathrm{s}]$ & $0.17 \pm 0.01$ & $0.15 \pm 0.04$ & $0.20 \pm 0.08$ & $0.09 \pm 0.10$ \\
\hline $\mathrm{QS}[\mathrm{mm} / \mathrm{s}]$ & $2.17 \pm 0.03$ & $1.66 \pm 0.11$ & $0.74 \pm 0.16$ & $0.54 \pm 0.20$ \\
\hline Contribution [\%] & $65.0 \pm 0.5$ & $15.6 \pm 1.5$ & $7.0 \pm 2.5$ & $12.6 \pm 2.5$ \\
\hline \multicolumn{5}{|c|}{ Diabetic donor, control } \\
\hline $\mathrm{CS}[\mathrm{mm} / \mathrm{s}]$ & $0.16 \pm 0.01$ & $0.18 \pm 0.04$ & $0.11 \pm 0.03$ & \\
\hline $\mathrm{QS}[\mathrm{mm} / \mathrm{s}]$ & $2.18 \pm 0.04$ & $1.71 \pm 0.11$ & $0.58 \pm 0.06$ & \\
\hline Contribution [\%] & $61.3 \pm 0.5$ & $18.5 \pm 1.5$ & $20.2 \pm 1.5$ & \\
\hline \multicolumn{5}{|c|}{ Diabetic donor, after irradiation } \\
\hline $\mathrm{CS}[\mathrm{mm} / \mathrm{s}]$ & $0.16 \pm 0.01$ & $0.14 \pm 0.08$ & $0.15 \pm 0.05$ & $0.05 \pm 0.05$ \\
\hline QS $[\mathrm{mm} / \mathrm{s}]$ & $2.14 \pm 0.05$ & $1.70 \pm 0.26$ & $0.61 \pm 0.20$ & $0.40 \pm 0.20$ \\
\hline Contribution [\%] & $62.3 \pm 0.5$ & $9.4 \pm 2.5$ & $17.1 \pm 2.5$ & $11.2 \pm 2.5$ \\
\hline
\end{tabular}

\section{DISCUSSION}

RBCs are extensively used in studies of aging processes related to the ROS action because their membrane is rich in polyunsaturated lipids and hemoglobin is a strong catalyst of free radical reactions which may initiate lipid peroxidation. Therefore the RBC, being a unique carrier of oxygen, is highly susceptible to oxidative stress. It is known that peroxidation of lipids and membrane proteins alters membrane fluidity, ion transport and defensive enzymatic activities in the cell (Chiu et al., 1989; Sangeetha et al., 2005) and thus membrane oxidation may influence the intrinsic properties of RBC, in particular the $\mathrm{Hb}$ state. For example, it has been shown that the oxidative stress leads to the formation of stable complexes between $\mathrm{Hb}$ molecules and proteins of the RBC membrane skeleton (Snyder et al., 1985). Moreover, during aging a significant decrease of the activities of many enzymes is observed in RBCs, as for example SOD, CAT or GPx (Sangeetha et al., 2005). A reduced glutathione level is accompanied by a decrease of - $\mathrm{SH}$ groups of proteins, which suggests a direct protective role of glutathione (Asgary et al., 2005). As glutathione is a reducing agent used by $\mathrm{GPx}$, which protects cells from oxidative stress, depletion of glutathione caused a proportional decrease of GPx activity (Spector et al., 1993). SOD and CAT participating in $\mathrm{O}_{2}{ }^{--}$scavenging and $\mathrm{H}_{2} \mathrm{O}_{2}$ decomposition into water and oxygen, respectively, are also important for maintaining the integrity of membrane structures (Snyder et al., 1985; Köteles, 1982).

We chose healthy and diabetic RBCs as subjects of our studies because it is known that the activities of important antioxidant enzymes are altered in diabetic cells than the unmodified one. In particular, it has been shown that glycated $\mathrm{Cu}, \mathrm{Zn}-\mathrm{SOD}$ has a lower enzymatic activity and its content is significantly higher in diabetic
RBCs than in normal controls (Kawamura et al., 1992; Arai et al., 1987; Kotake et al., 1998). On the other hand, a decreased activity of $\mathrm{Cu}, \mathrm{Zn}-\mathrm{SOD}$ accompanies an increased activity of CAT in diabetic RBCs (Błaszczak et al., 2005). Moreover, it was shown that in diabetes there is an increase in glycooxidation and lipooxidation products and in products of reaction of proteins with dicarbonyl compounds formed by nonoxidative mechanisms and therefore in this case one should talk about carbonyl stress. A function of glutathione was recognized as the crucial protective mechanism (Baynes et al., 1999) and it was found that there is a decrease in erythrocyte glutathione concentrations in clinical human diabetic cases (Thornalley et al., 1996). It is well proven that the mechanisms of radiation-induced biomolecular damage involve the generation of free radicals followed by their attack on proteins, lipids and carbohydrates (Hannig et al., 2000). Gamma irradiation can cause a variety of membrane changes which occur also during the aging processes, described above, for example lipid peroxidation, hydrolysis of phospholipid head groups, lipid-lipid or lipid-protein crosslinking, disulfide bridge formation, and amino acid residue damage in membrane proteins (Szweda-Lewandowska et al., 1989; Lee et al., 1994; Petkau, 1971; Graeub, 1994; Szweda-Lewandowska et al., 2003; Komorowska et al., 2007; Selim et al., 2009). Therefore due to the alteration of many enzymatic pathways in diabetic RBCs resulting in a strong modification of the lipid and protein membrane components one could predict that the ionizing $\gamma$-radiation applied in our studies would influence the stability of the healthy and diabetic cells in a different way. Indeed, we observed different susceptibilities of the diabetic and healthy RBCs to the action of $\gamma$-rays at the low doses between $0.04 \mathrm{mGy}$ and $1.8 \mathrm{mGy}$. Moreover, the degree of sensitivity of the RBC membranes allows us even to distinguish the stage of development of the disease. Our results show that diabetic RBCs are more sensitive to the action of $\gamma$-radiation at doses from 0.04 $\mathrm{mGy}$ to $1.2 \mathrm{mGy}$ exhibiting not only a higher degree of hemolysis but also a shift of observed characteristic transitions towards lower doses by about $0.2 \mathrm{mGy}$ and changes in the hemolysis behaviour within the characteristic irradiation time periods. The resistivity of diabetic RBCs is higher than that of healthy cells only for the doses $\geq 1.2 \mathrm{mGy}$. The Mössbauer measurements confirm that low doses of $\gamma$-radiation cannot alter the $\mathrm{Hb}$ states inside the RBC except at the highest applied dose of $1.8 \mathrm{mGy}$ which caused formation of modified $\mathrm{MetHb}_{\text {irr }}$ at about $12 \%$ of total $\mathrm{Hb}$ independently of 
the RBC type. Usually, much higher doses of $\gamma$-radiation were used to observe modifications of $\mathrm{Hb}$ (Szweda-Lewandowska et al., 1989; Oshtrakh et al., 1991). In addition, our experiments show that the $\mathrm{Hb}$ pool in diabetic $\mathrm{RBC}$ s contains a lower proportion of $\mathrm{OxyHb}$ but a higher one of MetHb. This is consistent with the observation that the percentage of glycated $\mathrm{Hb}$, which is unable to bind $\mathrm{O}_{2}$, increases in diabetic RBCs (Adak et al., 2008).

The distinct discontinuities and monotonic changes of hemolysis detected by us in the healthy and diabetic RBCs suggest that various enzymatic and chemical processes are activated inside the membranes under the action of low doses of $\gamma$ radiation. Their effects are stabilized within minutes. These mechanisms can be important for understanding the so called "by-stander" effects observed in new radiological approaches, in which two different doses of radiation separated in time are applied (Jayashree et al., 2001).

\section{Acknowledgements}

This work was partially supported by the Polish Ministry of Science and Higher Education, grant N N402 471337 (2009-2012), and its grants for Scientific Research (AGH WFiIS).

\section{REFERENCES}

Adak S, Chowdhury S, Bhattacharyya M (2008) Dynamic and electrokinetic behavior of erythrocyte membrane in diabetes mellitus and diabetic cardiovascular disease. Biochim Biophys Acta 1780: 108-115.

Agarwal P, Ray VL,Choudhury N, Choudhary RK (2005) Effect of pre-storage gamma irradiation on red blood cells. Indian J Med Res 122: $385-387$

Arai K, Maguchi S, Fujii S, Ishibashi H, Oikawa K, Taniguchi NJ (1987) Glycation and inactivation of human $\mathrm{Cu}-\mathrm{Zn}$-superoxide dismutase. Identification of the in vitro glycated sites. Biol Chem 262: 16969-16972.

Asgary S, Naderi GH, Askari N (2005) Protective effect of flavonoids against red blood cell hemolysis by free radicals. Exp Clin Cardiol 10: $88-90$.

Azzam EI, de Toledo SM,Gooding T, Little JB (1998) Intercellular Communication is involved in the bystander regulation of gene expression in human cells exposed to very low fluences of alpha particles. Radiat Res 150: 497-504.

Azzam EI, de Toledo SM, Little JB (2001) Direct evidence for the participation of gap-junction mediated intercellular communication in the transmission of damage signals from $\alpha$-particle irradiated to non-irradiated cells. Proc Nat Acad Sci USA 98: 473-478.

Bagchi K, Puri S (1998) Free radicals and antioxidants in health and disease. East Mediter Health J 4: 350-360.

Bannister JV, Bannister WH, Rotilio G (1987) Aspects of the structure, function, and applications of superoxide dismutase. CRC Crit Rev Biochem 22: 111-180.

Bashir S, Naik F, Cardigan R, Thomas S (2011) Effect of X-irradiation on the quality of red cell concentrates. Vox Sanguinis. DOI: $10.1111 /$ j.1423-0410.2011.01479.x

Baskar R (2010) Emerging role of radiation induced bystander effects. Cell communications and carcinogenesis. Genome Integrity 1: 1-8.

Baynes JW, Thorpe SR (1999) Role of oxidative stress in diabetic complications: a new perspective on an old paradigm. Diabetes 48: 1-9.

Baynes JW (1991) Role of oxidative stress in development of complications in diabetes. Diabetes 40: 405-412.

Benderitter M, Vincent-Genod L, Pouget JP, Voisin P (2003) The Cell Membrane as a Biosensor of Oxidative Stress Induced by Radiation Exposure: A Multiparameter Investigation. Radiat Res 159: 471-483.

Błaszczak R, Kędziora J, Ertel D, Rutkowski M, Kędziora-Kornatowska K, Kornatowski T, Rysz J, Kujawski K, Stachura D (2005) Selected antioxidative enzyme activities in patients with diabetes mellitus type 2. Arch Med Sci 1: 144-147.

Burda K, Hrynkiewicz A, Kołoczek H, Stanek J, Strzałka K (1995) Mixed valence state in ironporphyrin aggregates. Biochim Biophys Acta 1244: 345-350.

Burda K, Lekki K, Dubiel S, Cieślak J, Lekka M, Stanek J, Stachura Z (2002) Molecular mechanism of hemolysis caused by organometallic compounds. Appl Organometal Chem 10: 148-154.
Chelikani P, Fita I, Loewen PC (2004) Diversity of structures and properties among catalases. Cell Mol Life Sci 61: 192-208.

Chen WL, Luan YC, Shieh MC, Chen ST, Kung HT, Soong KL, Yeh YC, Chou TS, Mong SH, Wu JT, Sun CP, Deng WP, Wu MF, ShenML (2007) Effects of cobalt-60 exposure on health of taiwan residents suggest new approach needed in radiation protection. Dose-Response 5: 63-75.

Chiu D, Kuypers F, Lubin B (1989) Lipid peroxidation in human red cells. Semin Haematol 26: 257-276.

Cicha I, Suzuki Y, Tateishi N, Shiba M, Muraoka M, Tadokoro K, Maeda N (2000) Gamma-ray-irradiated red blood cells stored in mannitol-adenine-phosphate medium: rheological evaluation and susceptibility to oxidative stress. Vox Sang 79: 75-82.

Cohen BL (2008) The linear no-threshold theory of radiation carcinogenesis should be rejected. I Am Physical Sur 13: 70-76.

Dainiak D, Tan BJ (1995) Utility of biological membranes as indicators for radiation exposure: alterations in membrane structure and function overtime. Stem Cells 13: 142-152.

Dainiak N (1997) Mechanism of radiation injury: impact of molecular medicine. Stem Cells 15: 1-5.

Davey RJ, McCoy NC, Yu M, Sullivan JA, Spiegel DM, Leitman SF (1992) The effect of prestorage irradiation on posttransfusion red cell survival. Transf 32: 525-528.

Fasano F, Luban NLC (2008) Blood component therapy. Pediatr Clin $N A m$ 55: 421-445.

Feinendegen LE (2005) Evidence for beneficial low level radiation effects and radiation hormesis. Brit J Radiat 78: 3-7.

Graeub R (1994) Petkau effect, the devasting effect of nuclear radiation on buman health and the environment. 2nd edn. Four Walls Eight Windows.

Gwoździński K (1991) Ionizing radiation-induced structural modification of human red blood cells. Radiat Environ Biophys 30: 45-52.

Ha H, Kim KH (1999) Pathogenesis of diabetic nephropathy: the role of oxidative stress and protein kinase C. Diabetes Res Clin Pract 45: 147-151.

Hannig J, Lee RC (2000) Structural changes in cell membranes after ionizing electromagnetic field exposure. IEEE Trans Plasma Sci 28: 97-101.

Harman D (1992) Role of free radicals in ageing and disease. Ann N Y Acad Sci USA 673: 598-620.

Hirayama J, Abe H, Azuma H, Ikeda H (2005) Leakage of potassium from red blood cells following gamma ray irradiation in the presence of dipyridamole, trolox, human plasma or mannitol. Biol Pharm Bul 28: 1318-1320.

Iyer R, Lehnert BE (2002) Low dose, low-LET ionizing radiation-induced radioadaptation and associated early responses in unirradiated cells. Mut Res 503: 1-9.

Jayashree B, Devasagayam TPA, Kesavan PC (2001) Low dose radiobiology: mechanistic considerations. Curr Sci 80: 515-523.

Johnson F, Giulivi C (2005) Superoxide dismutases and their impact upon human health. Mol Aspects Med 26: 340-352.

Kawamura N, Ookawara T, Suzuki K, Konishi K, Mino M, Taniguchi N (1992) Increased glycated Cu,Zn-superoxide dismutase levels in erythrocytes of patients with insulin-dependent diabetis mellitus. $J$ Clin Endocrinol Metab 74: 1352-1354.

Kim YK, Kwon EH, Kim DH, Won DI, Shin S, Suh JS (2008) Susceptibility of oxidative stress on red blood cells exposed to gamma rays: hemorheological evaluation. Clin Hemorbeo and Microcirc 40: 315-324.

Komorowska M, Krokosz A. Szweda-Lewandowska Z (2007) Radiation damage to human erythrocytes: Influence of the composition of medium. Rad Phys Chem 76: 1587-1593.

Kotake M, Shinohara R, Kato K, Hayakawa N, Hayashi R, Uchimura K, Makino M, Nagata M, Kakizawa H, Nakagawa H, Nagasaka A, Itoh M (1998) Reduction of activity, but no decrease in concentration, of erythrocyte $\mathrm{Cu}, \mathrm{Zn}$-superoxide dismutase by hyperglycaemia in diabetic patients. Diabet Med 15: 668-671.

Köteles GJ (1982) Radiation effects on cell membranes. Radiat Environ Biophys 21: 1-18.

Krokosz A, Szweda-Lewandowska Z (2006) Induction of transient radioresistance in human erythrocytes. Radiat Phys Chem 75: 967-976.

Lang G, Marshall W (1966) Mössbauer effect in some hemoglobin compounds. Proc Phys Soc 87: 3-34.

Lee SW, Ducoff HS (1994) The effects of ionizing radiation on avian erythrocytes. Rad Res 137: 104-110.

Lowenthal GC, Airey PL (1997) Practical applications of radioactivity and nuclear reactions. Cambridge: Cambridge University Press.

Mahmoud SS, El-Sakhawy E, Abdel-Fatah ES, Kelany AM, Rizk RM (2011) Effects of acute low doses of Gamma-radiation on erythrocytes membrane. Radiat Environ Biophys 50: 189-198.

Marnett L (1999) Lipid peroxidation-DNA damage by malon-dialdehyde. Mutat Res 424: 83-95.

Meister A (1994) Glutathione-ascorbic acid antioxidant system in animals. I Biol Chem 269: 9397-9400.

Meyers RA (1995) Molecular biology and biotechnology: a comprehensive desk reference. pp 1084. Wiley-vch Verlag Gmbh. 
Meyer C, Dostou J, Nadkarni V, Gerich J (1998) Effects of physiological hyperinsulinemia on systemic, renal and hepatic substrate metabolism. Am J Phys 275: F915-F921.

Mothersill C, Seymour C (2001) Radiation-induced bystander effects: past history and future directions. Radiat Res 155: 759-767.

Murakami K, Kondo T, Ohtsuka Y, Fujiwara Y, Shimada M, Kawakami Y (1989) Impairment of glutathione metabolism in erythrocytes from patients with diabetes mellitus. Metabolism 38: 753-758.

Nagamatsu S, Inoue N, Murakawa S, Matsui H (1986) Evaluation of sodium and potassium pump activity and number in diabetic erythrocytes. Acta Endocrinol 11: 69-74.

Nagasawa H, Little JB (1999) Unexpected sensitivity to the induction of mutations by very low doses of alpha-particle radiation: evidence for a bystander effect. Radiat Res 152: 552-557.

Oshtrakh MI, Semionkin VA (1991) Mössbauer effect study of gammairradiated human oxyhemoglobin. Radiat Environ Biophys 30: 33-44.

Padayatty SJ, Katz A, Wang Y, Eck P, Kwon O, Lee JH, Chen S, Corpe C, Dutta A, Dutta SK, Levine M (2003) Vitamin C as an antioxidant: evaluation of its role in disease prevention. $\mathrm{J} \mathrm{Am}$ Coll Nut 22: 18-35.

Pasini EM, Kirkegaard M, Mortensen P, Lutz HU, Thomas AW, Mann M (2006) In-depth analysis of the membrane and cytosolic proteome of red blood cells. Blood 108: 791-801.

Pelsynski MM, Moroff G, Luban NL, Taylor BJ, Quinones RR (1994) Effect of gamma irradiation of red blood cell units on T-cell inactivation as assessed by limiting dilution analysis: implications for preventing transfusion-associated graft-versus-host disease. Blood 83: 1683-1689.

Petkau A (1971) Radiation effects with a model lipid membrane. Canadian J Chem 9: 1187-1196.

Petkau A (1972) Effects of $22 \mathrm{Na}+$ on a phospholipid membrane. Health Phys 22: 239-244.

Preedy VR, Watson RR (2007) The encyclopedia of vitamin E. CABI Publishing.

Purohit SC, Bisby RH, Cundall RB (1980a) Structural modification of human erythrocyte membranes following gamma-irradiation. Int $\mathrm{J}$ Radiat Biol 38: 147-158.

Purohit SC, Bisby RH, Cundall RB (1980b) Chemical damage in gamma irradiated human erythrocyte membranes. Int $J$ Radiat Biol 38: 159-166

Radivoyevitch T, Kozubek S, Sachs RK (2002) The risk of chronic myeloid leukemia: can the dose-response curve be U-shaped? Radit Res 157: 106-109.

Rancourt DG, Ping J-Y (1991) Voigt-based methods for arbitraryshape static hyperfine parameter distributions in Mössbauer spectroscopy. Nucl Instr Meth B 58: 85-87.

Resmi H, Pekcetin C, Güner G (2001) Erythrocyte membrane and cytoskeletal protein glycation and oxidation in short-term diabetic rabbits. Clin Exp Med 1: 187-193.

Riley PA (1994) Free radicals in biology: oxidative stress and the effects of ionizing radiation. Int J Radiat Biol 65: 27-33

Sangeetha P, Balu M, Haripriya D, Panneerselvam C (2005) Age associated changes in erythrocyte membrane surface charge: Modulatory role of grape seed proanthocyanidins. Exp Geront 40: 820-828.

Selim NS, Desouky OS, Ali SM, Ibrahim IH, Ashry HA (2009) Effect of gamma radiation on some biophysical properties of red blood cells membrane. Romanian J Biophys 19: 171-185.

Selim NS, Desouky OS, El-Marakby SM, Ibrahim IH, Ashry HA (2009) Rheological properties of blood after whole body gammairradiation. Iran J Radiat Res 7: 11-17.

Shapiro B, Kollman G (1968) The nature of membrane injury in irradiated human erythrocytes. Radiat Res 34: 335-346.

Sies H, and Stahl W (1995) Vitamins E and C, beta-carotene, and other carotenoids as antioxidants. Am J Clin Nutr 62: 1315S-1321S.

Snyder LM, Fortier NL, Trainor J, Jacobs J, Leb L, Lubin D, Chiu D, Shohet S, Mohandas N (1985) Effect of hydrogen peroxide ex- posure on normal human erythrocyte deformability, morphology, surface characteristics, and spectrin-hemoglobin cross-linking. Clin Invest 76: 1971-1977.

Sgouros G, Knox SJ, Joiner MC, Morgan WF, Kassis AI (2007) MIRD continuing education: bystander and low-dose-rate effects: are these relevant to radionuclide therapy? J Nuc Med 48: 1683-1691.

Spector A, Wang GM, Wang RR, Garner WH, Moll H (1993) The prevention of cataract caused by oxidative stress in cultured rat lenses by $\mathrm{H}_{2} \mathrm{O}_{2}$ and photochemically induced cataract. Curr Eye Res 12: $163-179$.

Stevens MJ, Obrosova I, Cao X, Van Huysen C, Greene DA (2000) Effects of DL-alpha-lipoic acid on peripheral nerve conduction, blood flow, energy metabolism, and oxidative stress in experimental diabetic neuropathy. Diabetes 49: 1006-1015.

Suzdalev JP (1988) Gamma resonance spectroscopy of proteins in model systems. pp 270. Moscow, Nauka (in Russian).

Szweda-Lewandowska Z, Puchata M, Osmulski PA, Rosin J (1989) Radiation-induced changes of structural and functional properties of human hemoglobin. II. Structural and functional characterization of irradiated deoxyhemoglobin. Radiat Environ Biophys 28: 42-58.

Szweda-Lewandowska Z, Krokosz A, Gonciarz M, Zajeczkowska W, Puchala M (2003) Damage to human erythrocytes by radiationgenerated HO. radicals: Molecular changes in erythrocyte membranes Free Radic Res 37: 1137-1143.

Thornalley PJ, McLellan LTW, Benn J, Sonksen PH (1996) Negative association between erythrocyte reduced glutathione concentration and diabetic complications. Clin Sci 91: 575-582.

Treleaven J, Gennery A, Marsh J, Norfolk D, Page D, Parker A, Saran, Thurston J, Webb D (2011) Guidelines on the use of irradiated blood components prepared by the British Committee for Standards in Haematology blood transfusion task force. $\mathrm{Br} J$ Haematol 152: $35-51$.

Trosco JE, Inoue T (1997) Oxidative stress, signal transduction and intercellular communication in radiation carcinogenesis. Stem Cells 15: 59-67.

Tsun-Yee Chiu D, Liu TZ (1997) Free radical and oxidative damage in human blood cells. J Biomed Sci 4: 256-259.

Uzel N, Sivas A, Uysal M, Oz H (1987) Erythrocyte lipid peroxidation and glutathione peroxidase activities in patients with diabetes mellitus. Hom Metab 19: 89-90.

Venerando B, Fiorilli A, Croci G, Tringali C, Goi G, Mazzanti L, Curatola G, Segalini G, Massaccesi L, Lombardo A, Tettamanti G (2002) Acidic and neutral sialidase in the erythrocyte membrane of type 2 diabetic patients. Blood 99: 1064-1070.

Waczulíková I, Šikurová L, Bryszewska M, Rékawiecka K, Č́rsky J, O. Uličná O (2000) Impaired erythrocyte transmembrane potential in diabetes mellitus and its possible improvement by resorcylidene aminoguanidine. Bioelectrochem Bioenerg 52: 251-256.

Weiskopf RB, Schnapp S, Rouine-Rapp K, Bostrom A, Toy P (2005) Extracellular potassium concentration in red blood cell suspensions after irradiation and washing. Transfusion 45: 1295-301

Yoshida K, Hirokawa J, Tagami S, Kawakami Y, Urata Y, Kondo T (1995) Weakened cellular scavenging activity against oxidative stress in diabetes mellitus: regulation of glutathione synthesis and efflux. Diabetologia 38: 201-10.

Zaider M, Bardash M, Fung A (1994) Molecular damage induced directly and indirectly by ionizing radiation in DNA. Int $J$ Radiat Bio 66: 459-465.

Zhou H, Suzuki M, Randers-Pehrson G, Vannais D, Chen G, Trosko JE, Waldren CA, Hei TK (2001) Radiation risk to low fluences of alpha particles may be greater than we thought. Proc Nat Acad Sci USA 98: 14410-14415.

Zimmermann R, Schoetz AM, Frisch A, Hauck B, Weiss D, Strobel J, Eckstein R (2011) Influence of late irradiation on the in vitro RBC storage variables of leucoreduced RBCs in SAGM additive solution. Vox Sanguinis 100: 279-284. 